\title{
Comparative analysis of length of stay, hospitalization costs, opioid use, and discharge status among spine surgery patients with postoperative pain management including intravenous versus oral acetaminophen
}

Ryan N. Hansen, An T. Pham, Elaine A. Böing, Belinda Lovelace, George J. Wan \& Timothy E. Miller

To cite this article: Ryan N. Hansen, An T. Pham, Elaine A. Böing, Belinda Lovelace, George J. Wan \& Timothy E. Miller (2017): Comparative analysis of length of stay, hospitalization costs, opioid use, and discharge status among spine surgery patients with postoperative pain management including intravenous versus oral acetaminophen, Current Medical Research and Opinion, DOI: 10.1080/03007995.2017.1297702

To link to this article: http://dx.doi.org/10.1080/03007995.2017.1297702

Accepted author version posted online: 20 Feb 2017.

Published online: 09 Mar 2017.

Submit your article to this journal \lceil

Џلl Article views: 3

Q View related articles ¿

View Crossmark data \lceil 


\title{
Comparative analysis of length of stay, hospitalization costs, opioid use, and discharge status among spine surgery patients with postoperative pain management including intravenous versus oral acetaminophen
}

\author{
Ryan N. Hansen ${ }^{a}$, An T. Pham ${ }^{\mathrm{b}, \mathrm{d}}$, Elaine A. Böing ${ }^{\mathrm{b}}$, Belinda Lovelace ${ }^{\mathrm{b}}$, George J. Wan ${ }^{\mathrm{b}}$ and Timothy E. Miller ${ }^{\mathrm{c}}$ \\ ${ }^{a}$ University of Washington, School of Pharmacy, Seattle, WA, USA; ${ }^{b}$ Mallinckrodt Pharmaceuticals, Health Economics and Outcomes Research

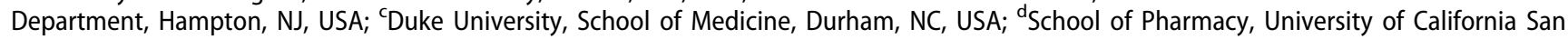 \\ Francisco, San Francisco, CA
}

\begin{abstract}
Background: Recovery from spine surgery is oriented toward restoring functional health outcomes while reducing resource use. Optimal pain management is a key to reaching these objectives. We compared outcomes of spine surgery patients who received standard pain management including intravenous (IV) acetaminophen (APAP) vs. oral APAP.

Methods: We performed a retrospective analysis of the Premier database (January 2012 to September 2015) comparing spine surgery patients who received pain management with IV APAP to those who received oral APAP, with no exclusions based on additional pain management. We performed multivariable logistic regression for the discharge and all cause 30-day readmission to the same hospital outcomes and instrumental variable regressions using the quarterly rate of IV APAP use for all hospitalizations by hospital as the instrument in two-stage least squares regressions for length of stay (LOS), hospitalization costs, and average daily morphine equivalent dose (MED) outcomes. Models adjusted for age, gender, race, admission type, 3M All Patient Refined Diagnosis Related Group severity of illness and risk of mortality, hospital size, and indicators for whether the hospital was an academic center and whether it was urban or rural.

Results: We identified 112,586 spine surgery patients with 51,835 (46\%) having received IV APAP. Subjects averaged 57 and 59 years of age respectively in the IV APAP and oral APAP cohorts and were predominantly non-Hispanic Caucasians and female. In our adjusted models, IV APAP was associated with 0.68 days shorter LOS (95\% Cl: -0.76 to $-0.59, p<.0001)$, $\$ 1175$ lower hospitalization costs $(95 \%$ $\mathrm{Cl}:-\$ 1611$ to $-\$ 739, p<.0001), 13 \mathrm{mg}$ lower average daily MED (95\% Cl: $-14 \mathrm{mg}$ to $-12 \mathrm{mg}$, $p<.0001), 34 \%$ lower risk of discharge to a skilled nursing facility (95\% Cl: 0.63 to $0.69, p<.0001)$, and $13 \%$ less risk of 30 -day readmission ( $95 \% \mathrm{Cl}$ : 0.73 to 1.03 ).

Conclusions: Compared to oral APAP, managing post-spine-surgery pain with IV APAP is associated with less resource use, lower costs, lower doses of opioids, and improved discharge status.
\end{abstract}

\section{ARTICLE HISTORY}

Received 7 November 2016 Revised 14 February 2017

Accepted 17 February 2017

\section{KEYWORDS}

Acetaminophen; comparative effectiveness; pain management; spine surgery

\section{Introduction}

The Institute for Healthcare Improvement (IHI) Triple Aim demands simultaneous pursuit of (1) improving the patient care experience, (2) advancing population health, and (3) reducing healthcare costs ${ }^{1,2}$. Applying this pursuit to postoperative care, recovery from spine surgery is oriented toward restoring functional health outcomes while reducing hospital length of stay (LOS) and medical expenditures. Optimal pain management in this population is a key to reaching these objectives, in addition to reducing the potential for chronic use of opioids ${ }^{3}$. The use of long-acting opioids for post-surgical pain has been demonstrated to be associated with increased health care utilization and costs ${ }^{4}$.

Prior research in multiple surgical areas including orthopedics, obstetrics, and general surgery suggests that multimodal pain management including IV acetaminophen (IV APAP) for acute post-surgical pain improves patient outcomes and reduces hospital resource use $\mathrm{s}^{5-9}$. Acetaminophen is a common component of multimodal pain management that may include both pharmaceutical and medical treatments. A recent review of multimodal pain management approaches in spine surgery suggests that APAP has the highest level of available evidence supporting its use ${ }^{3}$. Furthermore, a randomized placebo controlled trial has documented the ability of IV APAP to reduce pain scores after spine surgery ${ }^{10}$.

IV APAP may have some potential advantages over oral administration such as increased APAP concentrations in the cerebrospinal fluid and the ability to administer the medication to patients who are nauseous or unable to utilize oral medications ${ }^{11}$. In addition, concomitant use of oral APAP and opioids commonly used for post-surgical pain may result in inadequate pain control and lead to potential health safety risks due to gastric accumulation of APAP ${ }^{12}$. However, there

CONTACT Ryan N. Hansen rhansen@uw.edu E Pharmaceutical Outcomes Research and Policy Program, University of Washington, Box 357630, Seattle, WA 98195-7630, USA

(C) 2017 Informa UK Limited, trading as Taylor \& Francis Group

www.cmrojournal.com 
is a paucity of evidence on the comparative effectiveness of the route of administration of APAP in this population. We compared outcomes of spine surgery patients who received usual care pain management including either IV APAP or oral APAP.

\section{Patients and methods}

We performed a retrospective cohort study using data from the Premier Database between 1 January 2012 and 30 September 2015, expanding upon methods from a previously published study ${ }^{5}$. This database contains inpatient hospitalization and service records from member hospitals across the US. We used medical-record-level details of International Classification of Diseases, 9th Revision, Clinical Modification (ICD-9-CM) diagnosis and procedure codes, Current Procedural Terminology (CPT) medical procedure codes, and associated cost variables for this study.

We included all patients in the Premier Database with an ICD-9-CM procedure code for spine surgery (03.09, 03.4, 03.53, 03.59, 80.51, 81.02, 81.03, 81.05, 81.06, 81.07, 81.08, $81.32,81.37,81.62,81.63,84.51)$ that received either IV or oral APAP beginning on the day of surgery and continuing up to the third postoperative day. The administration of IV and oral APAP was identified from service records indicating a bill for one of the medications. Patients were separated into mutually exclusive groups based on their receipt of IV or oral APAP. Patients who received both IV and oral APAP during the first three postoperative days were not included in the analysis. No other exclusions were made, and all other pain management medications were allowed in both groups.

\section{Outcomes}

We pre-specified eight distinct outcomes of interest for this study and compared each between the two groups of spine surgery patients: (1) LOS for the hospitalization, (2) total cost of hospitalization, (3) mean dose of opioids billed; (4-6) opioid related complication rates: (4) nausea/vomiting, (5) respiratory depression (stratified by diagnosis, administration of naloxone, and mechanical ventilation), (6) constipation/ bowel obstruction (including ileus), (7) 30-day readmission to the same hospital, and 8) rate of discharge to skilled nursing care. Length of stay, total hospitalization costs, 30 day readmissions, and discharge status were captured from the hospitalization summary files. The mean morphine equivalent dose (MED) per day was calculated in milligrams starting on the day of admission using an algorithm from the Centers for Disease Control and Prevention ${ }^{13}$. The three opioid related complications were identified utilizing ICD-9-CM diagnosis codes, with naloxone and mechanical ventilation service codes augmenting the respiratory depression diagnosis.

\section{Statistical analyses}

We descriptively compared the IV APAP recipients to the oral APAP recipients in terms of age, gender, race, All Patient
Refined Diagnosis Related Groups Severity of Illness (APR-DRG SOI), APR-DRG Risk of Mortality (ROM), and the census region of the hospital. We used the chi-square test (for categorical variables) and Student's $t$-test (for continuous variables) to determine whether differences were significant across the exposure categories. Differences in each outcome were first compared descriptively using Student's $t$-test for continuous outcomes and unadjusted logistic regression for binary outcomes. We also calculated the proportion of patients within each group who received other analgesics by route and medication type from the day of surgery through discharge by counting the number of patients who received each analgesic and dividing by the total cohort size. Additionally, we subcategorized total costs by hospital department and performed multivariable logistic regressions for each binary outcome (complications, 30 day readmission, and discharge status) adjusting for all available patient demographics and hospital characteristics.

We also attempted to more closely replicate a nonobservational study through an exogenous factor (instrument) by estimating each hospital's rate of IV APAP use for all admissions on a quarterly basis. We constructed separate adjusted two-stage least squares instrumental variable regression models for LOS, total hospitalization cost, and opioid dose. Use of IV APAP (yes/no) was the main independent variable, instrumented by the time-varying quarterly rate of use of IV APAP. Patient demographics, year of admission, and hospital characteristics (bed size, rural/urban indicator, and teaching institution indicator) were included in both stages of the instrumental variable regressions.

This study was approved by the Human Subjects Division at the University of Washington by self-determination by the Principal Investigator. All analyses were conducted using SAS for Windows, Version 9.3 (SAS Institute Inc., Cary, NC, USA) and STATA 13 (StataCorp LP, College Station, TX, USA).

\section{Results}

We identified 112,586 spine surgery patients who received APAP, of whom 51,835 (46\%) had received IV APAP (Figure 1). Subjects averaged 57 and 59 years of age respectively in the IV APAP and oral APAP cohorts and were predominantly non-Hispanic Caucasians ( $>70 \%$ in both cohorts) and female (52\% and $55 \%$, respectively in the IV APAP and oral APAP cohorts). The majority of subjects ranked in the minor or moderate categories for the APR-DRG SOI and ROM (Table 1). Nearly $80 \%$ of the IV APAP cohort received IV APAP on the day of surgery, but only $16 \%$ received IV APAP on the first postoperative day. The use of IV APAP continued declining in the following two postoperative days. However, only $20 \%$ of the oral APAP cohort used oral APAP on the day of surgery, with $33 \%$ receiving oral APAP on the first postoperative day and $27 \%$ on the second postoperative day. The most common other analgesic for both groups was IV fentanyl followed by IV hydromorphone. But the use of oral analgesics varied between the groups, with more oral hydrocodone use in the IV APAP cohort and more oral oxycodone use in the PO APAP cohort (Table 2). 


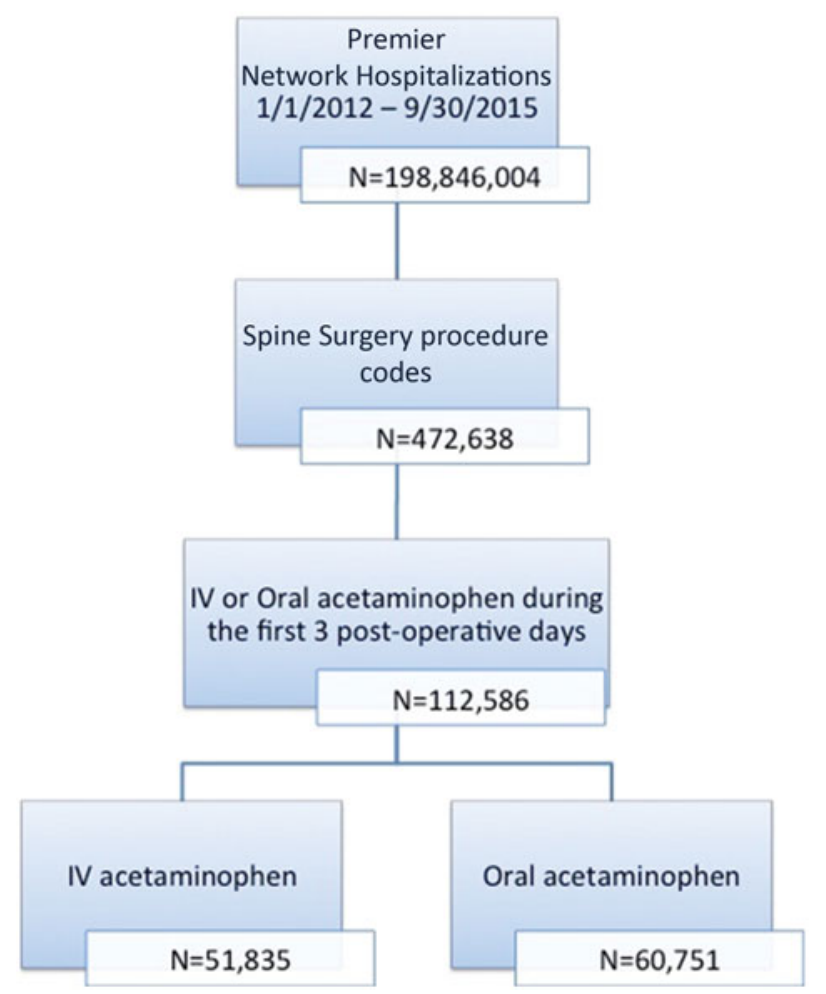

Figure 1. Study subject selection.

Table 1. Spine surgery population demographics.

\begin{tabular}{|c|c|c|c|}
\hline & $\begin{array}{c}\text { IV } \\
\text { Acetaminophen }^{\mathrm{a}} \\
(n=51,835)\end{array}$ & $\begin{array}{c}\text { Oral } \\
\text { Acetaminophen }^{\mathrm{a}} \\
(n=60,751)\end{array}$ & $p$-value \\
\hline $\begin{array}{l}\text { Age, mean (SD) } \\
\text { Female, } n(\%)\end{array}$ & $\begin{array}{r}57.2(14.9) \\
26,835(51.8)\end{array}$ & $\begin{array}{r}58.7(16.3) \\
33,224(54.7)\end{array}$ & $\begin{array}{l}<.0001 \\
<.0001\end{array}$ \\
\hline $\begin{array}{l}\text { Race, } n(\%) \\
\text { White } \\
\text { Black } \\
\text { Other } \\
\text { Unknown }\end{array}$ & $\begin{array}{r}41,411(79.9) \\
4781(9.2) \\
5600(10.8) \\
43(0.1)\end{array}$ & $\begin{array}{r}44,455(73.2) \\
5345(8.8) \\
10,872(17.9) \\
79(0.1)\end{array}$ & $<.0001$ \\
\hline $\begin{array}{l}\text { APR-DRG Severity of Illness, } n(\%) \\
\text { Minor } \\
\text { Moderate } \\
\text { Severe } \\
\text { Extreme }\end{array}$ & $\begin{array}{r}29,496(56.9) \\
17,465(33.7) \\
4166(8.0) \\
708(1.4)\end{array}$ & $\begin{array}{r}26,609(43.8) \\
23,351(38.4) \\
8184(13.5) \\
2607(4.3)\end{array}$ & $<.0001$ \\
\hline $\begin{array}{l}\text { APR-DRG Risk of Mortality, } n \text { (\%) } \\
\text { Minor } \\
\text { Moderate } \\
\text { Severe } \\
\text { Extreme }\end{array}$ & $\begin{array}{r}43,291(83.5) \\
6449(12.4) \\
1640(3.2) \\
455(0.9)\end{array}$ & $\begin{array}{r}44,742(73.7) \\
10,141(16.7) \\
4102(6.8) \\
1766(2.9)\end{array}$ & $<.0001$ \\
\hline $\begin{array}{l}\text { Emergent admission, } n(\%) \\
\text { Urban hospital, } n(\%) \\
\text { Teaching hospital, } n(\%) \\
\text { Hospital bed count, mean (SD) }\end{array}$ & $\begin{array}{r}9749(18.8) \\
46,423(89.6) \\
24,814(47.9) \\
484.1(252.3)\end{array}$ & $\begin{array}{l}11,087(18.3) \\
56,664(93.3) \\
35,308(58.1) \\
463.5(254.0)\end{array}$ & $\begin{aligned} & .02 \\
&<<.0001 \\
&<.0001 \\
&<.0001\end{aligned}$ \\
\hline $\begin{array}{l}\text { Year of hospitalization, } n(\%) \\
2012 \\
2013 \\
2014 \\
2015\end{array}$ & $\begin{array}{r}9496(18.3) \\
17,464(33.7) \\
16,462(31.8) \\
8413(16.2)\end{array}$ & $\begin{array}{l}19,675(32.4) \\
14,812(24.4) \\
13,060(21.5) \\
13,204(21.7)\end{array}$ & $<.0001$ \\
\hline $\begin{array}{l}\text { Hospital region, } n(\%) \\
\text { Midwest } \\
\text { Northeast } \\
\text { South } \\
\text { West }\end{array}$ & $\begin{array}{r}8804(17.0) \\
7793(15.0) \\
30,958(59.7) \\
4280(8.3)\end{array}$ & $\begin{array}{r}7952(13.1) \\
18,812(31.0) \\
24,291(40.0) \\
9696(16.0)\end{array}$ & $<.0001$ \\
\hline
\end{tabular}

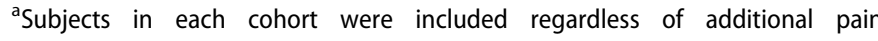
management.
Table 2. Spine surgery patients other analgesia from day of surgery to discharge.

\begin{tabular}{|c|c|c|c|c|}
\hline \multirow[t]{2}{*}{ Other IV Analgesics } & \multicolumn{2}{|c|}{$\begin{array}{c}\text { IV } \\
\text { Acetaminophen } \\
(n=51,835)\end{array}$} & \multicolumn{2}{|c|}{$\begin{array}{c}\text { Oral } \\
\text { Acetaminophen } \\
(n=60,571)\end{array}$} \\
\hline & $n$ & $\%$ & $n$ & $\%$ \\
\hline Fentanyl & 43,871 & 84.64 & 48,758 & 80.26 \\
\hline Hydromorphone & 40,749 & 78.61 & 46,159 & 75.98 \\
\hline Morphine & 26,881 & 51.86 & 27,599 & 45.43 \\
\hline Ketorolac & 8466 & 16.33 & 7133 & 11.74 \\
\hline Meperidine & 5108 & 9.85 & 4223 & 6.95 \\
\hline \multicolumn{5}{|l|}{ Other Oral Analgesics } \\
\hline Hydrocodone/Acetaminophen & 23,192 & 44.74 & 16,846 & 27.73 \\
\hline Oxycodone/Aspirin & 17,474 & 33.71 & 17,743 & 29.21 \\
\hline Oxycodone & 11,138 & 21.49 & 25,045 & 41.23 \\
\hline Aspirin & 3293 & 6.35 & 5297 & 8.72 \\
\hline Tramadol & 3197 & 6.17 & 4989 & 8.21 \\
\hline Hydromorphone & 3056 & 5.90 & 7865 & 12.95 \\
\hline
\end{tabular}

Other IV analgesics with $<5 \%$ use in either group: dihydroergotamine, methadone, nalbuphine, ibuprofen, buprenorphine, oxymorphone, meperidine/promethazine, butorphanol, codeine, fentanyl/droperidol. Other oral analgesics with $<5 \%$ use in either group: morphine, codeine/acetaminophen, ibuprofen, acetaminophen/caffeine/butalbital, methadone, tapentadol, tramadol/acetaminophen, meperidine, acetaminophen/phenyltoloxamine, ketorolac, oxymorphone, pentazocine/naloxone, codeine, hydrocodone/ibuprofen, aspirin/ caffeine/butalbital, fentanyl, acetaminophen/aspirin/caffeine, acetaminophen/ caffeine/butalbital/codeine, acetaminophen/diphenhydramine, diflunisal, salsalate, pentazocine/acetaminophen, isometheptene/dichloralphenazone/acetaminophen, salicylate comb., buprenorphine. Each subject was allowed to contribute up to once per other analgesic. The percentages presented use the whole study group (IV or oral acetaminophen) as the denominator.

\section{Length of stay}

The mean unadjusted LOS for IV APAP patients was 3.2 days (SD 3.8) compared to 4.9 days (SD 6.5) with oral APAP, a statistically significant difference of -1.6 days $(p<.0001)$ (Table 3). The instrumental variable regression estimated that IV APAP was associated with 0.68 days shorter hospitalization (95\% Cl: -0.76 to $-0.59, p<.0001$ ) (Table 4).

\section{Hospital costs}

Average unadjusted hospitalization costs were $\$ 24,800$ (SD $\$ 20,713$ ) for IV APAP patients and $\$ 29,366$ (SD \$28,817) for oral APAP patients, also significantly lower by $\$ 4566$ $(p<.0001)$ (Table 3$)$. At the department level, IV APAP recipients had higher specialist $(p<.0001)$ and anesthesia costs, but oral APAP recipients had higher surgery, room and board, pharmacy, diagnostic imaging, physical medicine and rehabilitation, laboratory, blood bank, respiratory, IV therapy, and other costs (all $p<.0001$ ), with the largest unadjusted differences observed in room and board (\$2409) and surgery (\$945) (Figure 2). The instrumental variable regression estimated that IV APAP was associated with $\$ 1175$ lower hospitalization costs $(95 \% \mathrm{Cl}:-\$ 1611$ to $-\$ 739, p<.0001)$ (Table 4).

\section{Opioid consumption}

The average opioid MED for IV APAP patients was $43.1 \mathrm{mg}$ (SD 55.2) and $50.8 \mathrm{mg}$ (SD 66.6) for oral APAP patients, an unadjusted difference of $-7.7 \mathrm{mg}(p<.0001)$ (Table 3$)$. 
Table 3. Unadjusted outcomes comparing IV and oral acetaminophen.

\begin{tabular}{|c|c|c|c|c|}
\hline & $\begin{array}{l}\text { IV Acetaminophen }{ }^{\mathrm{a}} \\
(n=51,835)\end{array}$ & $\begin{array}{l}\text { Oral Acetaminophen }{ }^{\text {a }} \\
\quad(n=60,751)\end{array}$ & Difference $(95 \% \mathrm{CI})$ & $p$-value \\
\hline Length of stay (days), mean (SD) & $3.2(3.8)$ & $4.9(6.5)$ & $-1.6(-1.70$ to -1.58$)$ & $<.0001$ \\
\hline Hospitalization cost $(\$)$, mean (SD) & $24,799.6(20,712.9)$ & $29,366.0(28,817.3)$ & $-4566.4(-4864.2$ to -4268.7$)$ & $<.0001$ \\
\hline Morphine equivalent dose (mg/day), mean (SD) & $43.1(55.2)$ & $50.8(66.6)$ & $-7.7(-8.4$ to -7.0$)$ & $<.0001$ \\
\hline Complications & & & Odds ratio $(95 \% \mathrm{Cl})$ & \\
\hline Bowel obstruction, $n(\%)$ & $2795(5.4)$ & $4437(7.3)$ & $0.72(0.69$ to 0.76$)$ & $<.0001$ \\
\hline Nausea/vomiting, $n(\%)$ & $957(1.9)$ & $1522(2.5)$ & $0.73(0.68$ to 0.79$)$ & $<.0001$ \\
\hline Respiratory depression, $n(\%)$ & $2367(4.6)$ & $4836(8.0)$ & 0.55 (0.53 to 0.58$)$ & $<.0001$ \\
\hline Discharge/readmission & & & Odds Ratio (95\% C.I.) & \\
\hline Discharge to skilled nursing facility, $n(\%)$ & $3386(6.5)$ & $7193(11.9)$ & $0.52(0.50$ to 0.54$)$ & $<.0001$ \\
\hline 30-day readmission to the same hospital, $n$ (\%) & $234(0.5)$ & $357(0.6)$ & $0.78(0.65$ to 0.91$)$ & $<.0001$ \\
\hline
\end{tabular}

${ }^{a}$ Subjects in each cohort were included regardless of additional pain management.

Table 4. Instrumental variable regressions comparing IV and oral acetaminophen patients ${ }^{\mathrm{a}}$.

\begin{tabular}{lrrrr}
\hline & Difference & $\begin{array}{r}\text { 95\% Confidence } \\
\text { interval }\end{array}$ & $p$-value \\
\hline Length of stay (days) & -0.68 & -0.76 & -0.59 & $<.0001$ \\
Hospitalization cost (\$) & -1175.23 & -1611.11 & -739.35 & $<.0001$ \\
Morphine equivalent dose (mg/day) & -13.0 & -14.14 & -11.86 & $<.0001$ \\
\hline awo-stage least squares with quarterly rate of IV acetaminophen use at the \\
hospital as the instrument. Adjusted for patient age, gender, race, APR-DRG \\
Severity of Illness and Risk of Mortality, year of admission, admitting phys- \\
ician type, hospital type (academic), hospital location (urban/rural), and num- \\
ber of beds. Oral acetaminophen is the reference group.
\end{tabular}

Our instrumental variable regression estimated that IV APAP was associated with $13 \mathrm{mg}$ lower average daily MED $(95 \% \mathrm{Cl}$ : $-14 \mathrm{mg}$ to $-12 \mathrm{mg}, p<.0001$ ) (Table 4).

\section{Potential opioid related complications}

Complication rates of bowel obstruction (odds ratio 0.72 , $95 \% \mathrm{Cl} 0.69$ to 0.76 ), nausea and vomiting (odds ratio 0.73 , 95\% Cl: 0.68 to 0.79 ), and respiratory depression (odds ratio $0.55,95 \% \mathrm{Cl}: 0.53$ to 0.58 ), were estimated to be significantly lower for IV APAP recipients in unadjusted analyses (all $p<.0001$ ) (Table 3), which held in multivariable logistic regressions (Table 5). The adjusted odds ratio for bowel obstruction was 0.93 ( $95 \% \mathrm{Cl}: 0.88$ to $0.98, p=.0041)$. The adjusted odds ratio for nausea and vomiting was $0.79(95 \%$ $\mathrm{Cl}: 0.73$ to $0.86, p<.0001)$. The adjusted odds ratio for respiratory depression was $0.91(95 \% \mathrm{Cl}: 0.85$ to 0.96 , $p=.0011)$.

\section{Hospital readmission and discharge}

IV APAP recipients were associated with a lower risk of readmission, with an odds ratio of $0.78(95 \% \mathrm{Cl}: 0.65$ to 0.91 , $p<.0001$ ) in unadjusted analyses (Table 2), but this was attenuated and no longer statistically significant in multivariable regression at an odds ratio of 0.87 (95\% Cl: 0.73 to 1.03 ) (Table 4). The unadjusted rate of discharge to skilled nursing was $48 \%$ lower (odds ratio: $0.52,95 \% \mathrm{Cl}: 0.50$ to 0.54 , $p<.0001$ ) (Table 3 ). This association held in the multivariable logistic regression for discharge to skilled nursing with an odds ratio of 0.66 for the IV APAP recipients ( $95 \% \mathrm{Cl}: 0.63$ to $0.69, p<.0001$ ) (Table 5).

\section{Discussion}

We found that spine surgery patients whose postoperative pain management included IV APAP were associated with shorter LOS, lower hospitalization costs, lower opioid doses, less complications, and lower rates of discharge to skilled nursing facilities compared to similar patients who were instead using oral APAP. The reduction in LOS of more than half a day and associated cost savings of over $\$ 1000$ are meaningful differences for hospitals in terms of efficiency and the opportunity to serve more patients. Coupling this with an important decrease in opioid dose of over $10 \mathrm{mg}$ MED per day is associated with meaningful and tangible outcomes for patients in terms of reduced rates of bowel obstruction (including ileus), nausea and vomiting, respiratory depression, and discharge to skilled nursing facilities. This represents a constellation of improved outcomes that benefit both patients and the hospitals caring for them.

There are also real financial implications of the reduction in discharges to skilled nursing facilities that are not included in our estimate of hospitalization costs. However, we can estimate the financial impact of the potentially avoided discharges to skilled nursing facilities using the odds ratio estimate. If we assume that those discharges incurred the median national cost of one week stay in a shared room $\left(\$ 6692 /\right.$ month divided by four $\left.{ }^{14}\right)$, the estimated cost savings resulting from using IV APAP in those who received oral APAP (34\% relative reduction to $7.8 \%$ or 4747 , a difference of 2446 discharges to skilled nursing) in our study is projected to be in excess of $\$ 4$ million dollars $(\$ 6692 / 4 \times 2446)$.

These findings are consistent with prior research in other surgical procedures, but to our knowledge represent the first real world study directly estimating the difference in effectiveness between IV and oral APAP. These findings also align with biological evidence of the potential interaction between morphine and oral APAP due to the inhibition of gastrointestinal motility by opioids, leading oral APAP to provide inadequate pain control in the surgical setting ${ }^{15}$. From the perspective of treatment protocol and medical policy development, this real world evidence is critical to help inform providers and hospital administrators about the benefits of IV APAP as part of multimodal analgesia ${ }^{5,6,16-18}$. The body of literature regarding the use of IV APAP for postoperative pain consistently finds associations supporting the use of IV APAP 


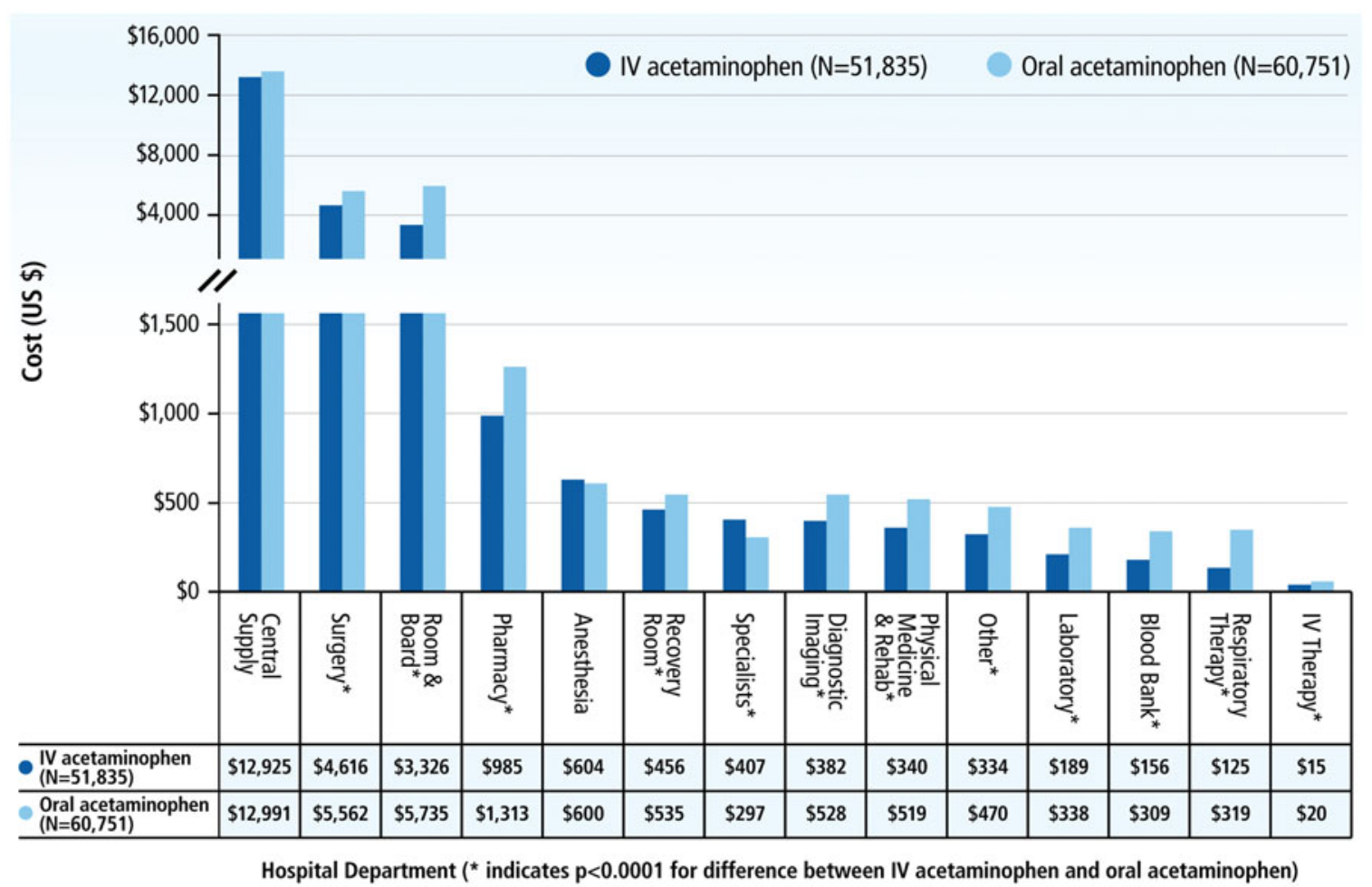

Figure 2. Unadjusted hospitalization costs by department comparing IV and oral acetaminophen.

Table 5. Multivariable logistic regression comparing IV and oral acetaminophen patients ${ }^{\mathrm{a}}$.

\begin{tabular}{llllr}
\hline & $\begin{array}{l}\text { Odds } \\
\text { Ratio }\end{array}$ & \multicolumn{2}{c}{$\begin{array}{c}95 \% \\
\text { Confidence } \\
\text { Interval }\end{array}$} & $p$-value \\
\hline $\begin{array}{l}\text { Complications } \\
\quad \text { Bowel obstruction }\end{array}$ & 0.93 & 0.88 & 0.98 & .0041 \\
$\quad \begin{array}{l}\text { Nausea/vomiting } \\
\text { Respiratory depression }\end{array}$ & 0.79 & 0.73 & 0.86 & $<.0001$ \\
$\begin{array}{l}\text { Discharge/readmission } \\
\quad \text { Discharge to skilled nursing } \\
\quad \text { facility }\end{array}$ & 0.91 & 0.85 & 0.96 & .0011 \\
$\begin{array}{l}\text { 30-day readmission to the } \\
\quad \text { same hospital }\end{array}$ & 0.87 & 0.63 & 0.69 & $<.0001$ \\
& & 0.73 & 1.03 & N.S. \\
\hline
\end{tabular}

${ }^{a}$ Adjusted for patient age, gender, race, APR-DRG Severity of Illness and Risk of Mortality, year of admission, admitting physician type, hospital type (academic), hospital location (urban/rural), and number of beds. Oral acetaminophen is the reference group.

N.S.: non-significant.

to improve patient outcomes and reduce hospitalization $\operatorname{costs}^{5,16-18}$.

\section{Limitations}

This study has several limitations that should be considered when evaluating the results presented above. The populations compared in each cohort were not randomly assigned and, although we applied techniques to attempt to control for selection bias, other unmeasured confounding of the association may still be present. One such source of confounding could be differences in regional anesthesia techniques or other analgesic medications that were used in the two cohorts. Our analyses did not control for the use of regional anesthesia and we acknowledge that, while it is uncommon, this may bias our findings. It is possible that differential use of another analgesic between the two groups could exacerbate or reduce the signals we observed. However, with the exception of the difference in choice of oral hydrocodone versus oral oxycodone between the two groups, this seems unlikely. Second, we were only able to observe readmission to the same hospital and thus the estimates of 30-day readmission may be biased. However, we have no reason to believe that this bias would be different between the IV and oral APAP groups, thus the estimated relative difference is unlikely to be impacted by this. Third, there are different types of spine surgeries and it is possible that within subgroups of surgeries there are different outcomes. We undertook a post-hoc subgroup analysis by adjusting for surgery type (discectomy, fracture, fusion, and laminectomy) in our multivariable regressions. Small changes in the effects were noted but the magnitude and statistical significance of the overall differences in all outcomes was unchanged.

Like all observational data sources, the Premier Database has a few unique limitations. The information related to administered medications is based on charges. As such, the actual dose of medications administered was not available. While it is accepted that utilization of opioids is likely lower than recorded based on Premier hospital audits, we do not expect any systematic differences between patients who receive IV versus oral APAP and thus the difference between our two groups of interest is expected to be a valid estimate. Although the database consists of an approximately $20 \%$ sample of hospitals in the US, they are not randomly sampled and some populations are likely under-represented. However, based on the large sample sizes in each cohort, we believe that this study represents the largest possible 
inpatient sample that spans both the private and publicly insured (Medicaid and Medicare) populations.

\section{Conclusion}

Compared to oral APAP, managing post-spine-surgery pain with IV APAP is associated with shorter LOS, decreased total hospitalization costs, lower doses of opioids, reduced risk of complications, and reduced risk of discharge to a skilled nursing facility. With the potential to assist in enhancing recovery and producing more cost-effective care than oral APAP, clinicians and hospital administrators managing the postoperative care of spine surgery patients should consider IV APAP in their multimodal pain management regimen as a means of targeting the IHI Triple Aim.

\section{Transparency}

\section{Declaration of funding}

This study was funded by Mallinckrodt Pharmaceuticals.

\section{Declaration of financial/other relationships}

R.N.H. has disclosed that he has received grants and consulting fees from Mallinckrodt Pharmaceuticals. A.T.P., B.L., and G.J.W. have disclosed that they are employees of Mallinckrodt Pharmaceuticals. T.E.M. and E.A.B. have disclosed that they have served as consultants for Mallinckrodt Pharmaceuticals.

CMRO peer reviewers on this manuscript have no relevant financial or other relationships to disclose.

\section{Acknowledgments}

No assistance in the preparation of this article is to be declared.

Previous presentation: This work was previously presented in part at the American Society of Regional Anesthesia and Pain Medicine 15th Annual Pain Medicine Meeting, San Diego, CA, USA, 17-19 November 2016.

\section{References}

1. Berwick DM, Nolan TW, Whittington J. The triple aim: care, health, and cost. Health affairs 2008;27:759-69

2. (IHI) IfHI. The IHI Triple Aim. 2016. Available at: http://www.ihi.org/ engage/initiatives/TripleAim/Pages/default.aspx [Last accessed 3 August 2016]

3. Devin CJ, McGirt MJ. Best evidence in multimodal pain management in spine surgery and means of assessing postoperative pain and functional outcomes. J Clin Neurosci 2015;22:930-8

4. Gold LS, Strassels SA, Hansen RN. Health care costs and utilization in patients receiving prescriptions for long-acting opioids for acute postsurgical pain. Clin J Pain 2016;32:747-54
5. Hansen RN, Pham A, Strassels SA, et al. Comparative analysis of length of stay and inpatient costs for orthopedic surgery patients treated with IV acetaminophen and IV opioids vs. IV opioids alone for post-operative pain. Adv Ther 2016;33:1635-45

6. Hansen RN, Pham AT, Balaban S, Wan GJ. Comparative analysis of inpatient costs for obstetrics and gynecology surgery patients treated with intravenous (IV) acetaminophen plus opioids or IV opioids alone for postoperative pain. J Women's Health 2016;25:A-15

7. Buvanendran A, Kroin JS. Multimodal analgesia for controlling acute postoperative pain. Curr Opin Anaesthesiol 2009;22:588-93

8. Elia N, Lysakowski C, Tramer MR. Does multimodal analgesia with acetaminophen, nonsteroidal antiinflammatory drugs, or selective cyclooxygenase- 2 inhibitors and patient-controlled analgesia morphine offer advantages over morphine alone? Meta-analyses of randomized trials. Anesthesiology 2005;103:1296-304

9. McDaid C, Maund E, Rice $S$, et al. Paracetamol and selective and non-selective non-steroidal anti-inflammatory drugs (NSAIDs) for the reduction of morphine-related side effects after major surgery: a systematic review. Health Technol Assess 2010;14:1-153, iii-iv

10. Cakan $\mathrm{T}$, Inan N, Culhaoglu $\mathrm{S}$, et al. Intravenous paracetamol improves the quality of postoperative analgesia but does not decrease narcotic requirements. J Neurosurg Anesthesiol 2008;20: 169-73

11. Singla NK, Parulan C, Samson R, et al. Plasma and cerebrospinal fluid pharmacokinetic parameters after single-dose administration of intravenous, oral, or rectal acetaminophen. Pain Pract 2012;12:523-32

12. Kennedy JM, Tyers NM, Davey AK. The influence of morphine on the absorption of paracetamol from various formulations in subjects in the supine position, as assessed by TDx measurement of salivary paracetamol concentrations. J Pharm Pharmacol 2003;55:1345-50

13. Dowell D, Haegerich TM, Chou R. CDC guideline for prescribing opioids for chronic pain - United States, 2016. JAMA 2016;315:1624-45

14. SkilledNursingFacilities.org. Nursing Home Costs by State. 2016. Available at: http://www.skillednursingfacilities.org/resources/nursing-home-costs/ [Last accessed 27 September 2016]

15. Devarakonda K, Lu L, Chen Y, et al. Morphine impacts the absorption of co-administered oral acetaminophen and results in altered pharmacokinetics in healthy subjects. American Society of Regional Anesthesia \& Pain Medicine. San Diego, CA, USA, 17-19 November 2016

16. Apfel C, Jahr JR, Kelly CL, et al. Effect of i.v. acetaminophen on total hip or knee replacement surgery: a case-matched evaluation of a national patient database. Am J Health Syst Pharm 2015;72:1961-8

17. Shaffer EE, Pham A, Woldman RL, et al. Estimating the effect of intravenous acetaminophen for postoperative pain management on length of stay and inpatient hospital costs. Adv Ther 2017;33:2211-28

18. Maiese BA, Pham AT, Shah MV, et al. Hospitalization costs for patients undergoing orthopedic surgery treated with intravenous acetaminophen (IV-APAP) plus other IV analgesics or IV opioid monotherapy for postoperative pain. Adv Ther 2016: published online 10 December 2016 doi: 10.1007/s12325-016-0449-8 